\title{
Determination of $\Upsilon$-aminobutyric acid (GABA) in Ziziphus Tuffahi fruit \& Earmotiun
}

\author{
Bushra Fadhil Ismael ${ }^{1}$, Firas Jameel Jabbar ${ }^{2}$, Abdulkareem M. Abd $^{3}$ \\ \{bushrafadhil1@gmail.com, firas.alassadi@stu.edu.iq, abdulkareem.abd@uobasrah.edu.iq\}
Department of Horticulture and Landscape Engineering, College of Agriculture, University of Basrah, $\operatorname{Iraq}^{1}$
Department of Pharmacy, Southern Technical University, Basra, Iraq ${ }^{2}$
College of Agriculture, University of Basra, Iraq ${ }^{3}$

\begin{abstract}
This study was conducted during the season 2020-2021 in the laboratories of the College of Agriculture, the University of Basra, and the Technical Institute of the Southern Technical University to study two types of buckthorn fruits, namely Tuffahi and Earmotiun fruits, and the concentration of GABA was estimated in both varieties before maturity and full maturity. (HPLC) was used to determine the concentration of this vital substance and the results showed the presence of this acid in a higher concentration in the fresh phase of both cultivars, while the concentration of GABA in the pome fruit was higher than in the Emotion fruit. and microorganisms. It has many important and health-promoting functions. There are not many studies about this acid and its presence in plants, so this study aimed to confirm the presence of this acid in the fruits of buckthorn.
\end{abstract}

Keywords: GABA, HPLC, Ziziphus, Tuffahi, Earmotiun, ZT1, ZE2.

\section{Introduction}

GABA (Gamma-Aminobutyric Acid) is a non-protein, four-carbon amino acid found in plants, animals, and microbes. This acid is an inhibitory neurotransmitter in the brain that affects personality and stress management. It is a metabolic product of plants and microorganisms created by decarboxylation of glutamic acid [1-3]. Detected in a variety of traditional foods resulting from microbial fermentation, these foods are safe and environmentally friendly. It also has the potential to offer new health-beneficial products rich in GABA. Since glutamate decarboxylase catalyses the synthesis of GABA, the best fermentation conditions are largely determined by the biochemical properties of the enzyme [4-7]. In a study tea leaves, mulberry leaves, tomatoes, animals, lactic acid bacteria (LAB), yeasts, and melds all were found to contain GABA. [8-10]. Tempeh (fermented soybeans) Dade (fermented buffalo milk), Assam durian (fermented durian), bar singsong (fermented cassava), ikan budu (fermented fish), sake, sake yogurt, sourdough, raspberry beer, kimchee cheese, and zeltar All are examples of fermented foods and drinks that contain GABA [11-12]. The presence of $\Upsilon$-aminobutyric acid (GABA) has also been detected in the fruits of sea buckthorn, which is widely cultivated in the warm tropical regions of Asia, Africa, and Europe [13]. The fruits contain many important chemical compounds in addition to nutrients, such as vitamins, sugars, organic acids, alkaloids, polyphenols, and saponins [14]. Buckthorn fruits are popular with a taste that is acceptable to most people. It is widely consumed in Asian countries as a food, in addition to being used as a folk medicine for thousands of years [15] used to relax and improve sleep [16]. In the past few 
years, the fruit has been commonly used to treat tiredness, fatigue, and anaemia. Several studies have emerged confirming the use of buckthorn in the treatment of some tumours, as an antiinflammatory, memory improvement, and liver preventative, in addition to its calming effect [17-20]. Minerals such as potassium, calcium, sodium, and others are known for their importance to human health. To live a healthy life, these components must be present in sufficient proportions in the human diet [21]. The chemical composition of jujube, which plays an essential function in human health, is unknown. There has been little research on the mineral composition of jujube fruit and leaves [22, 23]. The majority of studies focused on the content of the pulp and seed oil. These oils constitute 12.35 percent and 37.5 percent of the dry weight of the pulp and seeds, respectively, and are used for medicinal and pharmaceutical applications (blood pressure, antioxygen, hypothermic) [24-26]. The present study was conducted to determine the concentration of the active substance GABA (gamma-aminobutyric acid) in two cultivars of buckthorn fruits during the pre-ripening and full-ripening phases, that is, in February and March, respectively. The fruits were collected from the trees of the Hartha orchard, north of Basra Governorate, and the two cultivars Al-Tuffahi and Al-Armouti.

\section{Chemicals and Equipment}

Sigma-Aldrich provided the $\Upsilon$--aminobutyric acid (GABA) (St Louis, MO, USA). Methanol, ortho-phthalaldehyde (OPA), $\beta$-mercaptoethanol (BME), sodium tetraborate, ascorbic acid, formic acid, and other analytical grade chemicals were obtained via HPLC from Media Company, Inc (Fairfield, USA). J\&K Chemical Ltd provided the information (Shanghai) A Shimadzu liquid chromatography system comprising an LC-20AD solvent delivery system (pump), an SPD-20A photodiode array reagent, and a SIL-20ACHT injector with a $50 \mu \mathrm{ling}$ volume was used for HPLC chromatography. For data collection and processing, use LC version 1.25. (Shimadzu, Japan). For this study, a Princeton SPHER C18 (25 cm $4.6 \mathrm{~mm} \mathrm{ID,} \mathrm{5)} \mathrm{was}$ used. Preparation of samples.

\subsection{Preparation of Samples}

To estimate the concentration of $\Upsilon$-aminobutyric acid (GABA) in both pre-ripening and fully ripened buckthorn cultivars, samples were collected from both Tuffahi and Earmutiun cultivars in February and March from one of the Hartha orchards. In the north of Basra Governorate. The samples were kept in special bags and transported directly to the laboratory at room temperature. The samples were washed in distilled water, then cut into small strips, then dried, and ground into a powder using an electric mill. Finally, all samples were wrapped in straw bags and stored at $\left(-20{ }^{\circ} \mathrm{C}\right)$ for the analysis process.

\subsection{Extraction of Samples For Analysis Using Sonication Technology}

To perform the analysis process using HPLC technology, samples must be extracted from the two cultivars used in this study, Tuffahi and Earmutiun, deionized water is added to the precrushed samples and sonication is performed at room temperature for 60 minutes, thousands of Vacuum small bubbles in the solution during sonication. Cavitation is the process of bubbles breaking down in a solution. This causes intense vibrational vibrations in the cavity field, shattering chemical connections like those between water molecules, separating clumps of molecules, and enabling mixing. When dissolved gas is vibrated, for example, gas bubbles clump together and exit the solution more easily. The sound waves' energy causes friction in the solution, which produces heat. To stop a sample from heating up and insulting. After the 
sonication was terminated, the extract was centrifuged at $3000 \mathrm{rpm}$ for $20 \mathrm{~min}$. The supernatant was separated and stored at $0^{\circ} \mathrm{C}$ for analysis by HPLC technology.

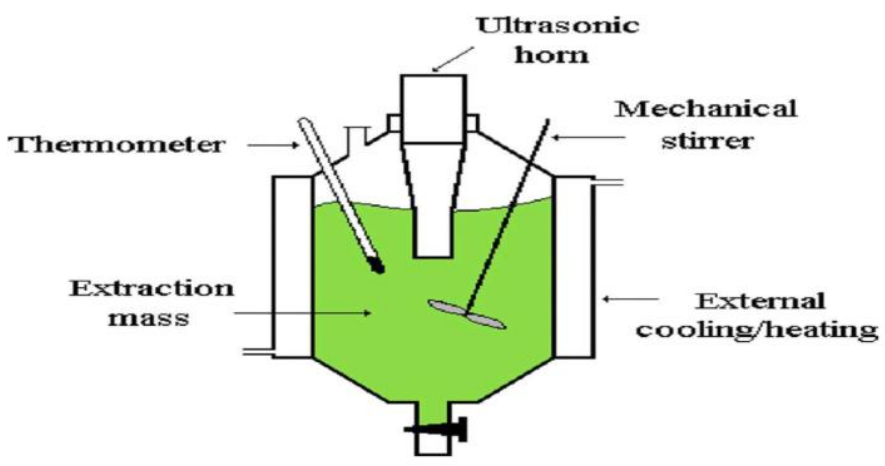

Fig 1. Sonication instrument for extraction of GABA.

\subsection{Preparation of Derivatization Reagent}

A derivation reagent has been made. As follows, $150 \mathrm{mg}$ o-phthaldialdehyde was combined with $3 \mathrm{~mL}$ methanol, $27 \mathrm{~mL} 0.1 \mathrm{M}$ tetraborate sodium (pH 9.5), $500 \mu$ l-mercaptoethanol, and $30 \mathrm{mg}$ ascorbic acid in a mixture that included $3 \mathrm{mM}$ methanol.

\section{a) HPLC Analysis}

$500 \mu \mathrm{l}$ of sample was combined with an equivalent volume of derivatization reagent, vortexed for 20 seconds, filtered, and injected into the HPLC apparatus for analysis. At $336 \mathrm{~nm}$, the GABA spectrum was obtained. Methanol (a) and 0.05 percent formic acid were used as rinse solvents (b). The injection volume was $12 \mu \mathrm{l}$ and the flow rate was $0.6 \mathrm{ml}$ per minute. The gradient programme went like this: $0-14$ minutes: $30 \%$ - $25 \%$ of b; $14-19$ minutes: $24 \%-32 \%$ of $b$; $19-25$ minutes: $34 \%$ of $b ; 19-25$ minutes: $34 \%$ of $b$.

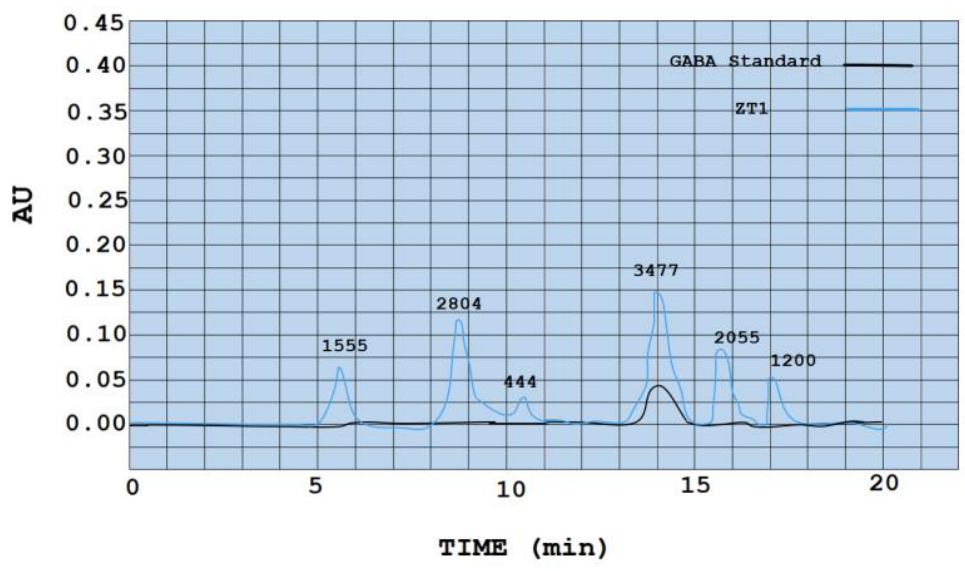

Fig 2. HPLC chromatograms of GABA from standard and ZT1 fruit. 


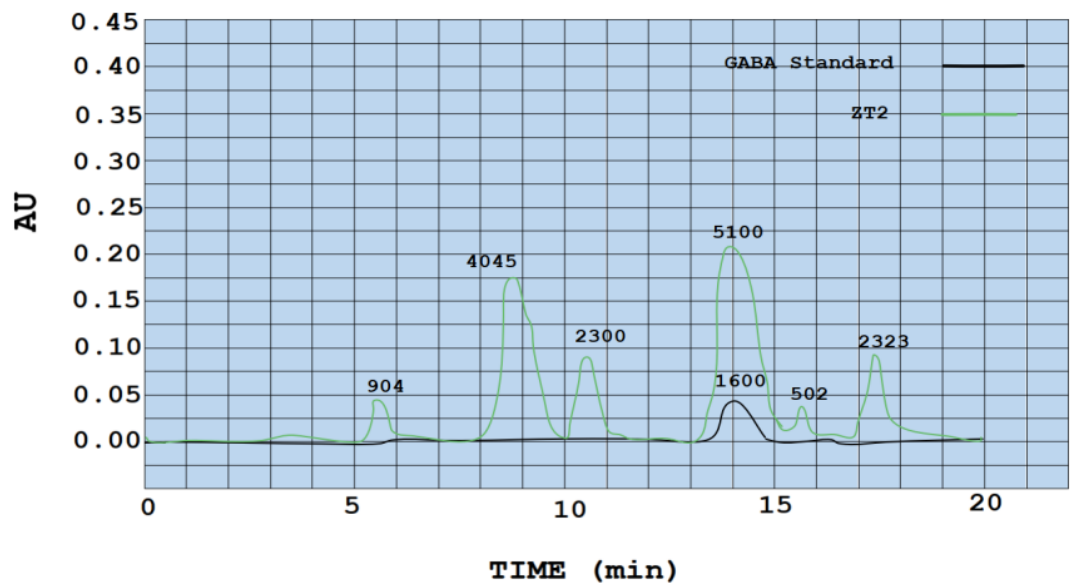

Fig 3. HPLC chromatograms of GABA from standard and ZT2 fruit.

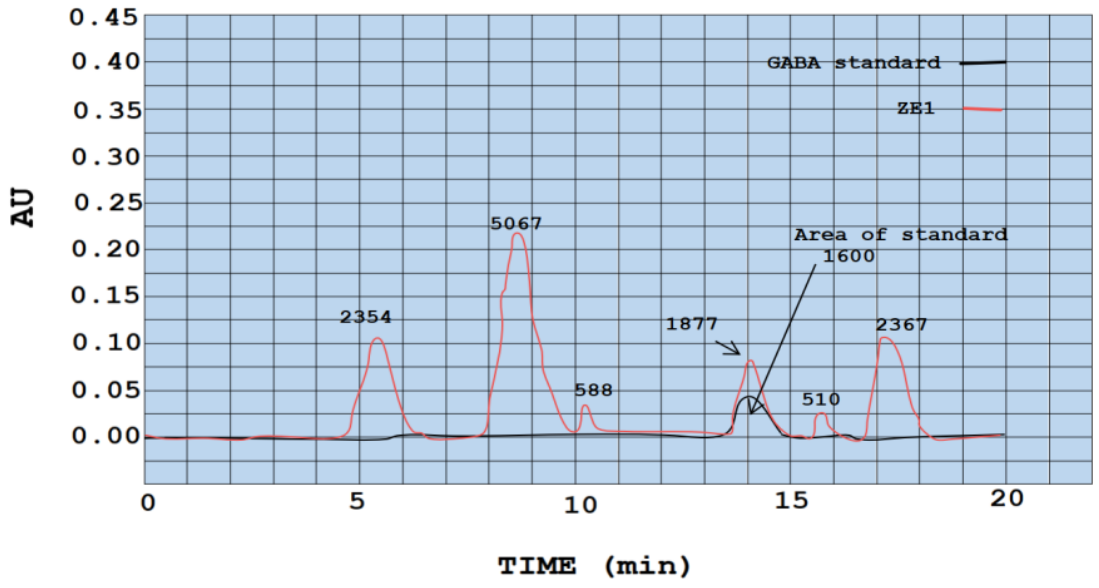

Fig 4. HPLC chromatograms of GABA from standard and ZE1 fruit.

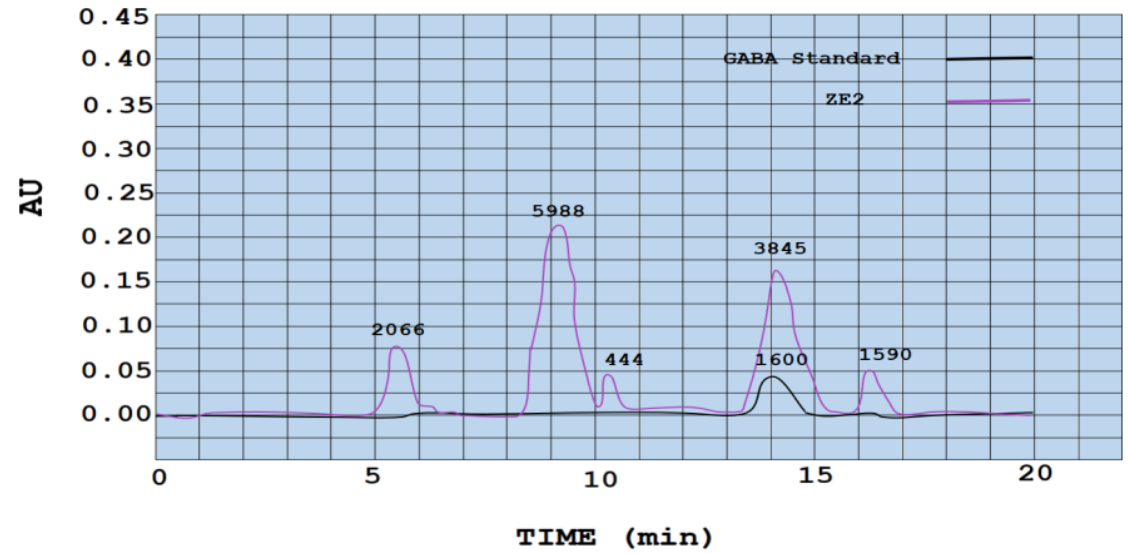

Fig 5. HPLC chromatograms of GABA from standard and ZE2 fruit. 


\subsection{Preparation of standard solution}

Methanol was used to make the stock standard solution with $230 \mu \mathrm{g} / \mathrm{mL}$ beta-aminobutyric acid (GABA).

\section{b) Calibration of GABA.}

For the linearity studies, nine different concentrations of $\Upsilon$-aminobutyric acid (GABA) were used. Peak area versus concentration showed a linear calibration curve for all samples in the $100-900 \mu \mathrm{g} / \mathrm{ml}$ concentration range. The linear regression equations for GABA are found to be $\mathrm{Y}=5.5947 \mathrm{X}+278.67$. The calculated regression coefficient values $(0.9983)$ indicated a high degree of linearity.

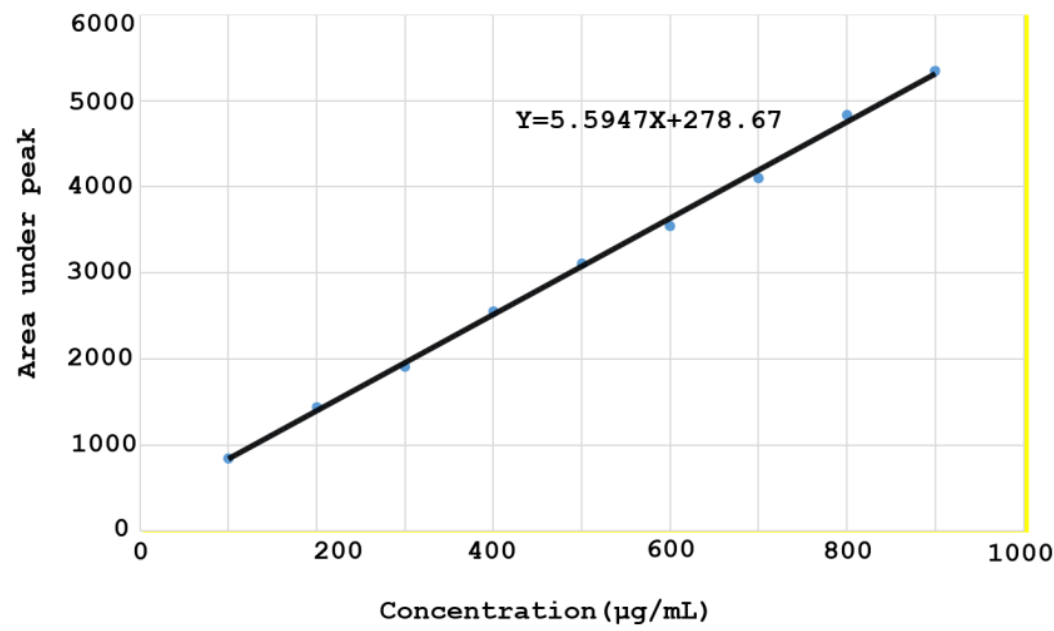

Fig 6. Shown the calibration curve of GABA.

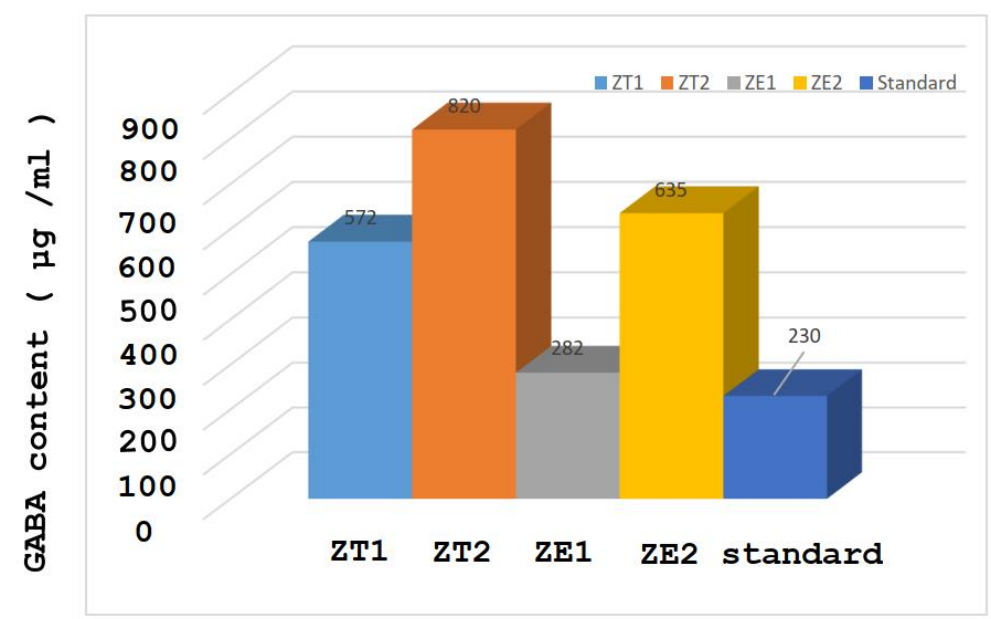

Fig 7. Shown the GABA content in several ziziphus fruits. 


\section{Results and Discussion}

Figures (2-5) show the chromatography of the GABA standard and four samples (ZT1, ZT2, ZE1, and ZE2), and the results of HPLc are shown in Table (1). The concentration of GABA in ripe Tuffahi and Earmutin was higher than that in unripe sea buckthorn fruits where the concentrations were all the following [ZT1 $(572 \mu \mathrm{g} / \mathrm{ml}), \mathrm{ZT} 2(840 \mu \mathrm{g} / \mathrm{ml}), \mathrm{ZE} 1(282 \mu \mathrm{g} / \mathrm{ml})$ and ZE2 (635) micrograms/ml.

Table 1. Show the concentration of GABA in Ziziphus fruit.

\begin{tabular}{|c|c|c|}
\hline Samples & $\begin{array}{l}\text { The area under the curve } \\
\text { (AUC) }\end{array}$ & Conc of GABA $(\mu \mathrm{g} / \mathrm{ml})$ \\
\hline ZT1 & 3477 & 572 \\
\hline ZT2 & 5100 & 840 \\
\hline ZE1 & 1877 & 282 \\
\hline ZE2 & 3845 & 635 \\
\hline GABA Standard & 1600 & 230 \\
\hline
\end{tabular}

As a result, the therapeutic effect of GABA depends on the amount of sea buckthorn consumed during food. For example, Diana presented her research on the amount of (GABA) a person consumes to influence blood pressure reduction and discovered that a daily intake (10-70 mg) is effective in lowering blood pressure. The same study also found that eating an amount (200 g) of ripe buckthorn has a significant sedative effect [27]. In another study conducted by (Okay) and others on several volunteers, each of them ate an amount (26.4 g) of (GABA) and found that this substance leads to a reduction in sleep disturbances, insomnia, and depression. (65\%) of them [28]. The researcher (Lnoue) conducted a study on 39 patients with moderately high blood pressure, ranging in age from $(28$ - 81) years, with an average of (54). Year. They were given a dose of GABA with fermented milk. And the researcher found a decrease in their blood pressure within $(2-4)$ weeks [29].

\section{Conclusion}

From the current study, we find that GABA is present in the fruits of Tuffahi and Earmotiun. We also found that "the percentage of (GABA) substance increases during the stages of the growth process to reach the peak concentration at the freshness and full maturity. Also, it was found in this study that there is a greater percentage of (GABA) in the fruits of Tuffahi compared to the fruits of Earmotiun.

\section{References}

[1]. Adeghate, E.; Ponery, A.S. (2002). GABA in the endocrine pancreas: cellular localization and function in normal and diabetic rats. Tissue Cell 34, 1-6.

[2]. Aoki, H.; Uda, I.; Tagami, K.; Furuya, Y.; Endo, Y.; Fujimoto, K. (2003). The production of a new tempeh like fermented soybean containing a high level of $\gamma$ - aminobutyric acid by anaerobic incubation with Rhizopus. Biocsi. Biotechnol. Biochem 67(5), 1018-1023.

[3]. Blanc, P.J.; Loret, M.O.; Santerre, A.T.; Pareilleux, A.; Prome, D.; Prome, J.C.; Laussac, J.P.; Goma, G. (1994). Pigment of Monascus J. Food Sci. 59, 862-865. 
[4] Li, H.; Qiu, T.; Huang, G.; Cao, Y. (2010). Production of gamma-aminobutyric acid by Lactobacillus brevis NCL912 using fed-batch fermentation. Microb. Cell Fact. 9, 85.

[5] Li, H.; Qiu, T.; Gao, D.; Cao, Y. (2010). Medium optimization for production of gammaaminobutyric acid by Lactobacillus brevis NCL912. Amino Acids 38, 1439-1445.

[6]. Li, Q.; Yao, H.Y.; Zhang, H. (2004). Studies on Screening for $\gamma$-aminobutyric acid producer and optimization of fermentation conditions. Chin. J. Amino Acids Biotic Res. 26(1), 40-43.

[7]. Lu, X.; Xie, C.; Gu, Z. (2008). Isolation of $\gamma$-aminobutyric acid-producing bacteria and optimization of fermentative medium. Biochem. Eng. J. 41, 48-52.

[8] Wu .C, Hsueh .Y.H, Kuo . G.H, Liu . S. J , Characterization of a potential probiotic Lactobacillus brevis RK03 and efficient production of $\gamma$-aminobutyric acid in batch fermentation, Int. J. Mol. Sci. 19 (143) (2018) 1-16.

[9] Hong . J , Kim . K, Biochemical and Biophysical Research Communications Crystal structure of g -aminobutyrate aminotransferase in complex with a PLP-GABA adduct from Corynebacterium glutamicum, Biochem. Biophys. Res. Commun. 514 (3) (2019) 601-606.

[10] Diana. M, Quílez. J, Rafecas .K, "Gamma-aminobutyric acid as a bioactive compound in foods : a review, J. Funct. Foods 10 (2014) 407-420.

[11] Kim.M.K.K, Isolation and identification of $\gamma$-aminobutyric acid ( GABA )-producing lactic acid bacteria from kimchi, J. Kor. Soc. Appl. Biol. Chem. 55

(2012) 777-785.

[12] Zhang.Q, Qing.S, T. Xiao, Z. Shuming, Z. Lin, T. Jie, X. Wenliang, Characterizatio of $\gamma$ aminobutyric acid ( GABA ) -producing Saccharomyces cerevisiae and coculture with Lactobacillus plantarum for mulberry beverage brewing, J. Biosci. Bioeng. 129 (4) (2019) 447-453.

[13] Hernández, F., Noguera-Artiaga, L., Burló, F., Wojdyło, A., Áa, C.-B.,Legua, P. (2016).

Physico-chemical, nutritional, and volatile composition and sensory profile of Spanish jujube (Ziziphus jujuba Mill.) fruits. Journal of the Science of Food and Agriculture, 96(8), 26822691.Huang, B. (2017). The Chinese Rural Statistc Yearbook. Beijing: China Statistic Press.

[14] Zhan, R., Xia, L., Shao, J., Wang, C., \& Chen, D. (2018). Polysaccharide isolated from Chinese jujube fruit (Zizyphus jujuba cv. Junzao) exerts anti-inflammatory effects through MAPK signaling. Journal of Functional Foods, 40, 461-470.

[15] Finotti, E., Bersani, E., Del Prete, E., \& Friedman, M. (2015). Application of a functional mathematical index (FMI) for predicting effects of the composition of jujube fruit on nutritional quality and health. Journal of Food Composition and Analysis, 42, 164-170.

[16] Chen, J., Zhonggui, L., Maiwulanjiang, M., Zhang, W. L., Zhan, J. Y. X.,Lam, C. T. W., ... Tsim, K. W. K. (2013). Chemical and biological assessment of Ziziphus jujuba fruits from China: Different geographical sources and developmental stages. Journal of Agricultural and Food Chemistry, 61(30), 7315-7324.

[17] Bai, L., Zhang, H., Liu, Q., Zhao, Y., Cui, X., Guo, S., ... Bai, N. (2016).Chemical characterization of the main bioactive constituents from fruits of Ziziphus jujuba. Food \& Function, 7(6), 2870-2877.

[18] Li, X., Li, X., Zhou, B., Man, S., Gao, W., \& Jing, S. (2017). Study on the bioactive constituents and in vitro antioxidant and in vivo anti-inflammatory activities of extracts from the fruits of ziziphus jujuba mill. cv. jinsixiaozao hort. Food Science and Technology Research, 23(3), 417-426.

[19] Pu, Y., Ding, T., Wang, W., Xiang, Y., Ye, X., Li, M., \& Liu, D. (2018). Effect of harvest, drying and storage on the bitterness, moisture, sugars, free amino acids and phenolic compounds of jujube fruit (Zizyphus jujube cv. Junzao). Journal of the Science of Food and Agriculture, 98(2),628-634.

[20] FNIC, (Food and nutrition information center) (internet addresses). http://warp. nal.usda.gov/ fnic/etext/000105.html (2008).

[21] Sena.L.P, D.J. Vanderjagt, Rivera.C, Tsin .A.CT.C, Muhamadu.I, Mahamadou.O, Millson.M , Pastuszyn.A and Glew. R.H, Plant Foods Human Nutr., 52, 17 (1998).

[22] Al-Kindy .S.M.Z, Abdulnour.A.O and M.M. Al-Rasbi, Sci. Technol., 6, 39 (2001).

[23].Montiel-Herrera.A , Campista-Leon .S , Camacho-Hernandez.I.L , Rios-Morgan .A and DelgadoVargas.F , Int. J. Food Sci. Nutr., 56, 587 (2005).

[24] Elaloui, M., Mguis, K., Laamouri, A., Albouchi, A., Cerny, M., Mathieu, C., Vilarem, G.,Hasnaoui, B., 2011. Fatty acids and sterols oils compositions of four Tunisian ecotypes of Ziziphus zizyphus (L.). H. Karst. Acta Bot. Gallica 159, 25-31.

[25] Elaloui, M., Laamouri, A., Albouchi, A., Cerny, M., Mathieu, C., Vilarem, G., Hasnaoui,B., 2014a. Chemical compositions of the Tunisian Z jujuba oil. Emir. J. Food Agric. 26, 602-608. 
[26] Elaloui, M., Laamouri, A., Fabre, J., Mathieu, C., Vilarem, G., Hasnaoui, B., 2014b. Distribution of free amino acids: polyphenols and sugars of Ziziphus jujube pulps harvested from plants grown in Tunisia. Nat. Prod. Res. 29, 94-97.

[27] Diana, M., Quilez, J., \& Rafecas, M. (2014). Gamma-aminobutyric acid as a bioactive compound in foods: A review. Journal of Functional Foods, 10, 407-420.

[28] Okada, T., Sugishita, T., Murakami, T., Murai, H., Saikusa, T., Horino, T., ...Takahashi, T. (2000). Effect of the defatted rice germ enriched with GABA for sleeplessness depression, autonomic disorder by oral administration. Journal of the Japanese Society for Food Science and Technology, 47(8), 596-603.

[29] Inoue, K., Shirai, T., Ochiai, H., Kasao, M., Hayakawa, K., Kimura, M., \& Sansawa, H. (2003). Blood-pressure-lowering effect of a novel fermented milk containing $\gamma$-aminobutyric acid (GABA) in mild hypertensives. European Journal of Clinical Nutrition, 57, 490-495. 